\title{
The concurrence of granulomatous inflammation in intrathoracic lymph nodes with regional metastasis from primary lung cancer in surgically resected specimens
}

The authors declare no financial disclosure

\begin{abstract}
Introduction: Granulomatous inflammation has been associated with malignancies such as breast, testicular, renal cell, and lymphoma. The coexistence of granulomatous inflammation in mediastinal/hilar lymph node with primary lung malignancy has been described in case reports.

Our goal was to examine the frequency of granulomatous reaction in mediastinal/hilar lymph node in the patients who had undergone surgical resection of lung cancer.

Material and methods: We performed a retrospective analysis of 40 patients (1) aged $\geq 18$ years and (2) who underwent lobectomy or pneumonectomy from August 1, 2012 to October 31, 2016 at Saint Louis University Hospital and (3) had pathology suggestive of cancer.

Results: Of those 40 patients, $3(7.5 \%)$ had granulomatous inflammation in the lymph nodes. None of these 3 individuals had evidence of metastasis in the particular lymph nodes with granulomatous inflammation.

Conclusion: Our small cohort revealed that the presence of granulomatous inflammation in a lymph node can be safely taken as an evidence of the absence of metastasis to the lymph node. This finding can obviate the need for further sampling for the particular lymph node with granulomatous inflammation and can decrease the sampling time.
\end{abstract}

Key words: biopsy, bronchoscopy, lung neoplasm, lymph nodes, sarcoidosis

\section{Introduction}

Granulomatous inflammation has been associated with breast and testicular malignancies, renal cell cancer, and lymphoma [1-3]. Additionally, historical studies have shown an increased risk of cancer in patients previously diagnosed with sarcoidosis, especially lung cancer and lymphoma [4]. This association had previously been termed sarcoid-like reaction and sarcoid cancer syndrome [5]. To date, the etiology of this phenomenon has yet to be elucidated. Sarcoid reaction is thought to be triggered by cytokines derived from tumor cells or antigens expressed by tumor cells [6, 7]. It is theorized that a T-cell mediated immunological hypersensitivity reaction to tumor cell antigens leads to granuloma formation [8]. These granulomatous reactions may occur within neoplasms or regional lymph nodes that are either affected or unaffected by tumor [1]. The frequency of such sarcoid reactions in carcinomas is $4.4 \%$ [9].

This raises unique challenges for pulmonary physicians, including false reassurance of benign disease when granulomatous inflammation is found on aspirates of pulmonary nodules, mas-

Address for correspondence: Setu Patolia, Division of Pulmonary and Critical Care, Saint Louis University, USA, e-mail: patoliasetu@gmail.com DOI: $10.5603 /$ ARM.2018.0034 
ses, and lymph nodes. Recently, endobronchial ultrasound transbronchial needle aspiration (EBUS-TBNA) has more frequently been employed for the sampling of mediastinal and hilar lymph nodes in cancer staging or work up of thoracic lymphadenopathy. Three previous studies examining EBUS-TBNA have shown that the presence of granulomatous inflammation on needle aspiration and the diagnosis of malignancy is mutually exclusive [10-12]. However, multiple case reports have been published that have shown the coexistence of granuloma and malignancy in the same lymph node on EBUS-TBNA [13, 14].

Our goal is to examine the granulomatous reaction to carcinoma in patients who have undergone lung resection and determine the frequency of coexisting of granulomatous inflammation with malignancy in mediastinal or hilar lymph nodes. This bears significant clinical importance as it can affect the sampling time of a lymph node and overall EBUS-TBNA procedure duration.

\section{Material and methods}

This is a retrospective study investigating the association between granulomatous inflammation and underlying malignancy in patients who underwent lung resection. The study was approved by the institution review board at Saint Louis University Hospital (IRB protocol Number 27539).We queried our electronic health record (EHR) for all patients admitted to Saint Louis University Hospital, a 356-bed tertiary university-affiliated facility in the Midwestern United States, from August 1, 2012 to October 31, 2016, with a procedure code which included lobectomy or pneumonectomy.

A total of 66 patients had undergone those procedures during the study period. Exclusion criteria were the following: (1) Resection was not completed; (2) Pathology data not available in EHR; or (3) Pathology negative for malignancy; (4) Pathology showing metastatic malignancy to the lung. Forty patients met criteria for inclusion in the study.

We collected data including age, gender, date of procedure, type of lung resection, the presence and location of granulomatous inflammation, existence of known granulomatous disease, presence of known fungal or mycobacterial infection, and when pertinent, pathologic stage of underlying malignancy according to the TNM staging system (seventh edition).

\section{Results}

Baseline demographics of the sample is shown in Table 1. Mean age of the study subjects was 64.82 years (range $30-80$ years). Twenty seven (67.5\%) patients were male, 2 (5\%) were Hispanic. Twenty five (62.5\%) subjects had upper lobes distribution of malignancy with $12(30 \%)$ in the right upper lobe, $21(52.5 \%)$ patients were diagnosed with adenocarcinoma while $14(35 \%)$ and $4(10 \%)$ with squamous cell and small cell histology, respectively. Thirty six (90\%) individuals were current or former smokers, 2 (5\%) and 1 (2.5\%) patients had history of latent tuberculosis and connective tissue disease, respectively. None of the subjects were diagnosed with sarcoidosis in the past.

There were 35 (87.5\%) patients that underwent lobectomy while 5 (12.5\%) subjects underwent pneumonectomy. Of those 40 patients, $3(7.5 \%)$ had evidence of granulomatous inflammation in mediastinal or hilar lymph nodes (Table 2). None of these 3 individuals had evidence of ma-

Table 1. Demographics

\begin{tabular}{|c|c|c|c|}
\hline & & $\mathrm{n}=\mathbf{4 0}$ & $\%$ \\
\hline \multirow[t]{2}{*}{ Age } & Mean & 64.82 & \\
\hline & Range & $30-80$ & \\
\hline \multirow[t]{2}{*}{ Sex } & Male & 27 & 67.5 \\
\hline & Female & 13 & 32.5 \\
\hline \multirow[t]{2}{*}{ Race } & Non Hispanic & 38 & 95 \\
\hline & Hispanic & 2 & 5 \\
\hline \multirow[t]{4}{*}{ Location } & LUL & 13 & 32.5 \\
\hline & LLL & 7 & 17.5 \\
\hline & RUL & 12 & 30 \\
\hline & RLL & 8 & 20 \\
\hline \multirow[t]{4}{*}{ Diagnosis } & Adeno & 21 & 52.5 \\
\hline & Small cell & 4 & 10 \\
\hline & Squamous cell cancer & 14 & 35 \\
\hline & Large cell & 1 & 2.5 \\
\hline \multirow{2}{*}{$\begin{array}{l}\text { Tobacco } \\
\text { use }\end{array}$} & Yes & 36 & 90 \\
\hline & No & 4 & 10 \\
\hline \multirow{4}{*}{$\begin{array}{l}\text { Medical } \\
\text { history }\end{array}$} & Latent TB & 2 & 5 \\
\hline & Fungal & 0 & 0 \\
\hline & $\begin{array}{l}\text { Connective tissue } \\
\text { disease }\end{array}$ & 1 & 2.5 \\
\hline & Sarcoidosis & 0 & 0 \\
\hline \multirow{2}{*}{$\begin{array}{l}\text { Surgical } \\
\text { resection } \\
\text { type }\end{array}$} & Lobectomy & 35 & 87.5 \\
\hline & Pneumonectomy & 5 & 12.5 \\
\hline
\end{tabular}


Table 2. Results

\begin{tabular}{cccccccc}
\hline $\begin{array}{c}\text { Age/ } \\
\text { /sex }\end{array}$ & $\begin{array}{l}\text { Procedure } \\
\text { performed }\end{array}$ & Location & $\begin{array}{c}\text { Granuloma } \\
\text { location }\end{array}$ & Malignancy & $\begin{array}{c}\text { Stage } \\
\text { (pathological) }\end{array}$ & $\begin{array}{c}\text { History of granulo- } \\
\text { matous disease }\end{array}$ & $\begin{array}{c}\text { History of fungal/ } \\
\text { /mycobacterial disease }\end{array}$ \\
\hline $60 \mathrm{~F}$ & Lobectomy & RUL & LN 4, 10 & NSCLC & T2aNOM0 & No & No \\
$60 \mathrm{M}$ & Lobectomy & RUL & LN 2 & NSCLC & T1aNOMO & No & No \\
$67 \mathrm{M}$ & Lobectomy & LUL & Mediastinal LN & NSCLC & T2aNOMx & No & No \\
\hline
\end{tabular}

lignancy in the lymph node with granulomatous inflammation.

\section{Discussion}

Granulomatous inflammation in the lymph nodes has been described in various malignancies. Granulomatous inflammation like sarcoidosis can also present as PET avid masses and lymphadenopathy. The significance of granulomatous inflammation found during EBUS TBNA rapid on site cytological exam has not been well studied in patients with suspected primary lung malignancies. Our study aimed to identify the concurrence of granulomatous inflammation and malignancy in patients who underwent lobectomy or pneumonectomy for early stage lung cancer.

In 1972, Brincker et. al. [4] reported granulomatous inflammation with underlying lymphoma in less than $1 \%$ of lymphomas. Various case reports have described concurrence of diverse cancers and granulomatous inflammation around the cancer tissue. Steinfort et al. [12] examined 187 patients who underwent mediastinoscopy, lobectomy or pneumonectomy. Eight out of 187 (4.3\%) had evidence of granulomatous inflammation in one of the sampled lymph node. However, none of these 8 patients had concurrent presence of malignancy and granulomatous reaction in the same lymph node. Kamiyoshihara et al. [15] reviewed 326 patients who underwent lobectomy. Granulomatous reaction was noted in 4 (1.2\%) patients. None of these individuals had malignancy and granulomatous inflammation present in the same lymph node.

Tomimaru et al. [16] studied 1733 patients undergoing surgical treatment for lung cancer between 1990-2004. Twenty two (1.3\%) subjects had granulomatous reaction in the resected lymph nodes. However, 4 out of 22 (18.2\%) individuals with granulomatous inflammation had concurrent malignancy in the same lymph node. Similarly, Jepsen et al. [17] examined 630 patients who underwent surgical resection of lymph node for lung cancer. Twenty (3.2\%) patients had granu- lomatous reaction in the sampled lymph node. However, 2 out of 20 (10\%) subjects with granulomatous inflammation in the lymph node had concurrent malignancy. Jepsen et al. [17] also noticed that squamous cell carcinoma histology was more likely to be associated with granulomatous inflammation in the lymph node. Bellinger et al. [18] examined 37 patients with extrathoracic malignancy and granulomatous inflammation in EBUS TBNA samples. On subsequent follow-up of the study subjects with surgical histology or radiography, it was determined that 2 (5.4\%) patients had false negative lymph node EBUS TBNA. Comparatively, our cohort revealed that in none of our patients the coexistence of granulomatous inflammation with malignancy in the resected lymph nodes occurred.

The significance of granulomatous lymphadenopathy in primary lung cancer is unclear. Steinfort et al. [19] examined 157 patients who underwent lobectomy. Eight subjects with granulomatous reaction in the lymph node were compared with 16 matched control patients. All of them were pNo at baseline. Disease recurrence was noted in 7 control individuals compared to none of the cases. The author concluded that sarcoidal reaction in the lymph node may predict lower rate of disease recurrence after resection. Grosu et al. [20] compared 44 patients with granulomatous inflammation with 62 subjects with benign mediastinal adenopathy. Both groups had history of lung cancer and had no active malignancy at the beginning of the study.

The presence of granulomatous inflammation did not confer survival benefit as compared to the absence of granulomatous inflammation - 3-year survival was $93 \%$ vs. $88 \%$, respectively ( $p=0.4$ ) [20]. Similarly, Kamiyoshihara et al. [15] did not find any significant difference in survival between the sarcoid group and control group.

The impact of these findings on clinical practice is substantial. EBUS time varies in different studies basing on the number of passes and the number of lymph nodes that are aspirated. Yasufuku et al. [21] examined the sensitivity 
of EBUS-TBNA in 102 patients. In his study, mean EBUS TBNA time was 14.9 minutes (4-29 minutes). Chrissian et al. [22] reported mean procedure time of 51 minutes in a fellowship environment when procedures were done under moderate sedation using propofol. Lee et al. [23] studied the number of aspirations required to obtain optimal results with EBUS TBNA. In the study, an average of 1.6 lymph nodes were sampled per procedure with an average of 4 passes per a lymph node. The mean time for the EBUS ranged from 21.6 minutes for one lymph node station to 60.3 minutes for 3 lymph node stations, with a reported average time of $33.4 \mathrm{mi}-$ nutes. Additionally, Lee et al. [23] suggested that procedure time would be shorter if fewer passes were done per a lymph node station. Basing on our study, if granuloma is found during Rapid On Site Evaluation, it can be safely concluded that the nodal enlargement is unlikely secondary to malignancy and further lymph node sampling can be avoided, thus reducing overall procedure time and sedation medication doses.

One of the major limitation of our study is a small sample size. Additionally, the study was performed at single academic center in the Midwestern United States, which limits its generalizability.

\section{Conclusion}

EBUS-TBNA is widely regarded as a type of a staging tool in lung cancer. Previous studies have shown that the presence of granulomatous inflammation on EBUS-TBNA and the diagnosis of malignancy are mutually exclusive [10-12]. However, multiple case reports demonstrate a significant correlation between coexisting granulomatous inflammation in the lymph nodes on EBUS-TBNA. Our single-center retrospective study revealed a significantly higher incidence of (7\%) of granulomatous inflammation in resected lymph nodes. But granulomatous inflammation was not associated with the presence of malignancy in resected lymph node in patients undergoing lobectomy and pneumonectomy. We believe further, larger, multicentered studies are needed to determine the true incidence and associated risk factors of concomitant granulomatous inflammation and malignancy.

\section{Conflicts of interest}

The authors declare no conflict of interest.

\section{References:}

1. Brincker H. Sarcoid reactions in malignant tumours. Cancer Treat Rev. 1986; 13(3): 147-156, indexed in Pubmed: 3536088.

2. Dick J, Begent RH, Meyer T. Sarcoidosis and testicular cancer: A case series and literature review. Urol Oncol. 2010; 28(4): 350-354, doi: 10.1016/j.urolonc.2008.09.029, indexed in Pubmed: 19070517.

3. Ouellet S, Albadine R, Sabbagh R. Renal cell carcinoma associated with peritumoral sarcoid-like reaction without intratumoral granuloma. Diagn Pathol. 2012; 7: 28, doi: 10.1186/1746-1596-7-28, indexed in Pubmed: 22424560.

4. Brincker H. Sarcoid reactions and sarcoidosis in Hodgkin's disease and other malignant lymphomata. Br J Cancer. 1972; 26(2): 120-123, indexed in Pubmed: 5038325.

5. Shigemitsu H. Is sarcoidosis frequent in patients with cancer? Curr Opin Pulm Med. 2008; 14(5): 478-480, doi: 10.1097/ MCP.0b013e328305bf7d, indexed in Pubmed: 18664979.

6. Haralambieva E, Rosati S, van Noesel C, et al. Florid granulomatous reaction in Epstein-Barr virus-positive nonendemic Burkitt lymphomas: report of four cases. Am J Surg Pathol. 2004; 28(3): 379-383, indexed in Pubmed: 15104301.

7. Kobayashi K, Kaneda K, Kasama T. Immunopathogenesis of delayed-type hypersensitivity. Microsc Res Tech. 2001; 53(4): 241-245, doi: 10.1002/jemt.1090, indexed in Pubmed: 11340669 .

8. Sehgal S, Goyal P, Ghosh S, et al. Malignancy and granulomatosis: causality of conincidence? Narrative systemic review. Iran J Pathol. 2014(9): 237-244.

9. Khurana KK, Stanley MW, Powers CN, et al. Aspiration cytology of malignant neoplasms associated with granulomas and granuloma-like features: diagnostic dilemmas. Cancer. 1998; 84(2): 84-91, indexed in Pubmed: 9570210.

10. Kennedy MP, Jimenez CA, Mhatre AD, et al. Clinical implications of granulomatous inflammation detected by endobronchial ultrasound transbronchial needle aspiration in patients with suspected cancer recurrence in the mediastinum. J Cardiothorac Surg. 2008; 3: 8, doi: 10.1186/1749-8090-3-8, indexed in Pubmed: 18298864.

11. DePew ZS, Gonsalves WI, Roden AC, et al. Granulomatous inflammation detected by endobronchial ultrasound-guided transbronchial needle aspiration in patients with a concurrent diagnosis of cancer: a clinical conundrum. J Bronchology Interv Pulmonol. 2012; 19(3): 176-181, doi: 10.1097/ LBR.0b013e31825f8eda, indexed in Pubmed: 23207457.

12. Steinfort DP, Irving LB. Sarcoidal reactions in regional lymph nodes of patients with non-small cell lung cancer: incidence and implications for minimally invasive staging with endobronchial ultrasound. Lung Cancer. 2009; 66(3): 305-308, doi: 10.1016/j.lungcan.2009.03.001, indexed in Pubmed: 19329219.

13. Trisolini R, Cancellieri A, Patelli M. May sarcoidal reaction and malignant features coexist in regional lymph nodes of non-small cell lung cancer patients? Lung Cancer. 2009; 66(2): 272-273, doi: 10.1016/j.lungcan.2009.08.005, indexed in Pubmed: 19733417.

14. Gilbert CR, Abendroth C, Yarmus LB. The Intranodal Presence of Coexisting Granulomatous Inflammation and Carcinoma During Transbronchial Needle Aspiration of Intrathoracic Lymphadenopathy. J Bronchology Interv Pulmonol. 2017; 24(1): 80-83, doi: 10.1097/LBR.0000000000000218, indexed in Pubmed: 27479015.

15. Kamiyoshihara M, Hirai T, Kawashima O, et al. Sarcoid reactions in primary pulmonary carcinoma: report of seven cases. Oncol Rep. 1998; 5(1): 177-180, indexed in Pubmed: 9458317.

16. Tomimaru Y, Higashiyama M, Okami J, et al. Surgical results of lung cancer with sarcoid reaction in regional lymph nodes. Jpn J Clin Oncol. 2007; 37(2): 90-95, doi: 10.1093/jjco/hyl141, indexed in Pubmed: 17272320.

17. Jepsen O, Laurberg P, Laurberg P. Sarcoid reactions in pulmonary neoplasms. Scand J Respir Dis. 1975; 56(1): 20-27, indexed in Pubmed: 1145149.

18. Bellinger CR, Sharma D, Ruiz J, et al. Negative Predictive Value of Granulomas on EBUS-TBNA in Suspected Extrathoracic Malignancy. Lung. 2016; 194(3): 387-391, doi: 10.1007/s00408016-9878-z, indexed in Pubmed: 27113372. 
19. Steinfort DP, Tsui A, Grieve J, et al. Sarcoidal reactions in regional lymph nodes of patients with early stage non-small cell lung cancer predict improved disease-free survival: a pilot case-control study. Hum Pathol. 2012; 43(3): 333-338, doi: 10.1016/j.humpath.2011.05.006, indexed in Pubmed: 21835432.

20. Grosu HB, Ost DE, Morice RC, et al. Mediastinal Granulomatous Inflammation and Overall Survival in Patients with a History of Malignancy. Ann Am Thorac Soc. 2015; 12(10): 1534-1541, doi: 10.1513/AnnalsATS.201506-318OC, indexed in Pubmed: 26284901.

21. Yasufuku K, Fleury Feith J. Cytological specimens obtained by endobronchial ultrasound-guided transbronchial needle aspiration: sample handling and role of rapid on-site evalu- ation. Ann Pathol. 2012; 32(6): e35-46, 421, doi: 10.1016/j. annpat.2012.09.212, indexed in Pubmed: 23244484.

22. Chrissian AA, Bedi H. Bronchoscopist-directed Continuous Propofol Infusion for Targeting Moderate Sedation During Endobronchial Ultrasound Bronchoscopy: A Practical and Effective Protocol. J Bronchology Interv Pulmonol. 2015; 22(3): 226-236, doi: 10.1097/LBR.0000000000000187, indexed in Pubmed: 26165893.

23. Lee HS, Lee GK, Lee HS, et al. Real-time endobronchial ultrasound-guided transbronchial needle aspiration in mediastinal staging of non-small cell lung cancer: how many aspirations per target lymph node station? Chest. 2008; 134(2): 368-374, doi: 10.1378/chest.07-2105, indexed in Pubmed: 18263688 . 